\title{
Synthesis of meso-substituted cationic porphyrins as potential photodynamic agents
}

\author{
Débora Lazzeri and Edgardo N. Durantini* \\ Departamento de Química, Universidad Nacional de Río Cuarto, Agencia Postal Nro 3, \\ 5800 Río Cuarto, Argentina \\ E-mail : edurantini@exa.unrc.edu.ar
}

\section{Dedicated to Professor Roberto A. Rossi and Professor Edmundo Rúveda}

(received 04 Jul 03; accepted 15 Sep 03; published on the web 24 Sep 03)

\begin{abstract}
Novel meso-substituted cationic porphyrins have been synthesized as potential photodynamic agents. 5,10-bis(4-Acetamidophenyl)-15,20-bis(4-methylphenyl)porphyrin 1 was prepared using a modification of the Alder-Longo procedure. However, two different approaches were compared in the synthesis of 5-(4-trifluorophenyl)-10,15,20-tris(4-acetamidophenyl)porphyrin 2. One involved a condensation of binary mixture of aldehydes and pyrrole under equilibrium conditions and the other a binary mixture of aldehydes and meso-(4acetamidophenyl)dipyrromethane 3 . The last synthetic pathway was advantageous mainly for an easier reaction work up and a higher yield. Both amido porphyrin $\mathbf{1}$ and $\mathbf{2}$ were hydrolyzed in basic media and treated with methyl iodide to form 5,10-di(4-methylphenyl)-15,20-di(4trimethylammonium phenyl)porphyrin iodide 4 and 5-(4-trifluorophenyl)-10,15,20-tris(4trimethyl ammoniumphenyl)porphyrin iodide 5, respectively. Porphyrin $\mathbf{5}$ bears a highly lipophilic trifluoromethyl group, which increases the amphiphilic character of the structure. On the other hand, the photodynamic properties of porphyrin 5 were changed forming metal complex with $\mathrm{Pd}(\mathrm{II})$, porphyrin 6. Absorption and fluorescence spectroscopic studies of these porphyrins were compared in different solvents. These amphiphilic cationic porphyrins are promising photosensitizers with potential applications in bacteria inactivation by photodynamic therapy.
\end{abstract}

Keywords: Cationic porphyrin, dipyrromethane, amphiphilic structure, palladium

\section{Introduction}

Tetrapyrrolic macrocycles occupy a central place in bioorganic chemistry. ${ }^{1}$ Meso-substituted porphyrins have recently found specific biomedical applications, particularly in the field of 
detection and treatment of neoplastic tissues. ${ }^{2,3}$ Photodynamic therapy (PDT) consists of the administration of a photosensitizer, which is selectively retained by the neoplastic tissue. The subsequent irradiation with visible light in the presence of oxygen specifically inactivates tumor cells. ${ }^{4,5}$ Adequate photosensitizers are deemed to have a high absorption coefficient in the visible region of the spectrum and have a triplet excited state, with a long lifetime, to efficiently produce $\mathrm{O}_{2}\left({ }^{1} \Delta_{\mathrm{g}}\right){ }^{6}$

Cationic porphyrins have several interesting features, which make these compounds attractive photosensitizers for a variety of biological systems. ${ }^{7-11}$ These porphyrins are able to interact with DNA bases, inducing DNA lesions upon photoactivation. ${ }^{12,13}$ Recently, cationic porphyrins have also shown important applications as sensitizers to photoinduce direct inactivation of multidrug resistant microorganisms. ${ }^{14}$ Gram-positive bacteria are susceptible to the photodynamic effect produced by neutral and anionic sensitizers. Gram-negative bacteria have only been inactivated in these conditions in the presence of an agent, which stimulates the membrane translocation of the porphyrins. ${ }^{15}$ However, studies with cationic porphyrin derivatives have been shown to photoinduce direct inactivation of Gram-negative bacteria without the presence of an additional permeabilization agent. ${ }^{16-18}$

The combination of hydrophobic and hydrophilic substituents in the sensitizer structure results in an intramolecular polarity axis, which can facilitate membrane penetration and produces a better accumulation in subcellular compartments, enhancing the effective photosensitization. ${ }^{19,20}$ This sensitizer architecture required the formation of asymmetrically meso-substituted porphyrins. These porphyrins containing two different types of mesosubstituents (A and B) can be prepared by a binary mixed aldehyde and pyrrole condensation. $^{21,22}$ This approach is statistical in nature and usually six porphyrins are formed, which involve $\mathrm{AABB}$ - and $\mathrm{AB}_{3}$-porphyrin patterns. ${ }^{23}$ However, the isolation of the desired porphyrin requires slow and careful chromatography for purification, the yield is very poor and obtaining pure porphyrin is not always possible. A convenient approach for the synthesis of meso-substituted trans-porphyrins (ABAB-porphyrins) has been developed from the condensation of dipyrromethane with an aldehyde in a MacDonald-type $2+2$ condensation. ${ }^{24,25}$ Also, condensation of a dipyrromethane with a binary mixture of aldehydes was used to obtain meso-substituted porphyrins bearing three identical substituents, $\mathrm{B}$ and one different $\mathrm{A}\left(\mathrm{AB}_{3}\right.$ porphyrins). ${ }^{26,27}$ In these cases, the structure $A$ bears a functional group, which can be used to link the porphyrin with other molecules, while B was used to change the macrocycle properties.

This paper reports the synthesis of novel asymmetrically meso-substituted cationic porphyrins with $\mathrm{AABB}$ - and $\mathrm{AB}_{3}$-porphyrin symmetry pattern, 5,10-bis(4-methylphenyl)-15,20bis(4-trimethylammoniumphenyl)porphyrin iodide 4 and 5-(4-trifluorophenyl)-10,15,20-tris(4trimethylammoniumphenyl) porphyrin iodide 5. Thus, 5,10-bis-(4-acetamidophenyl)-15,20bis(4-methylphenyl)porphyrin $\mathbf{1}$ was prepared from a binary mixture of aldehyde and pyrrole using a modification of the Alder-Longo procedure. On the other hand, two synthetic methods were compared in the formation of 5-(4-trifluorophenyl)-10,15,20-tris(4acetamidophenyl)porphyrin $\mathbf{2}$, which is a precursor of $\mathbf{5}$. These approaches involve the 
condensation of a binary mixture of aldehyde and, either pyrrole or dipyrromethane derivative, catalyzed by acid. Tricationic porphyrin $\mathbf{5}$ contains a trifluoromethyl group. The influence of the trifluoromethyl group in biologically active molecules is often associated with the increased lipophilicity that this substituent imparts. ${ }^{28-30}$ Also, fluorine porphyrin derivatives are suitable candidates for application in diagnosis and therapy of cancer. ${ }^{31,32}$ The positive charges were incorporated at the peripheral position to increase the amphiphilic character of the structure. The photodynamic properties of porphyrin 5 were changed by forming a metal complex with $\mathrm{Pd}(\mathrm{II})$ 6. ${ }^{33}$ The coordination of tetrapyrrilic macrocycles with palladium produces an increase in the triplet state production, which improves the photodynamic activity of these sensitisers. ${ }^{33,34,35}$

\section{Results and Discussion}

\section{Synthesis}

5,10-bis(4-Acetamidophenyl)-15,20-bis(4-methylphenyl)porphyrin 1 was synthesized from a binary mixture of aldehydes and pyrrole using a modification of the Alder-Longo method as showed in Scheme $1 .^{36}$

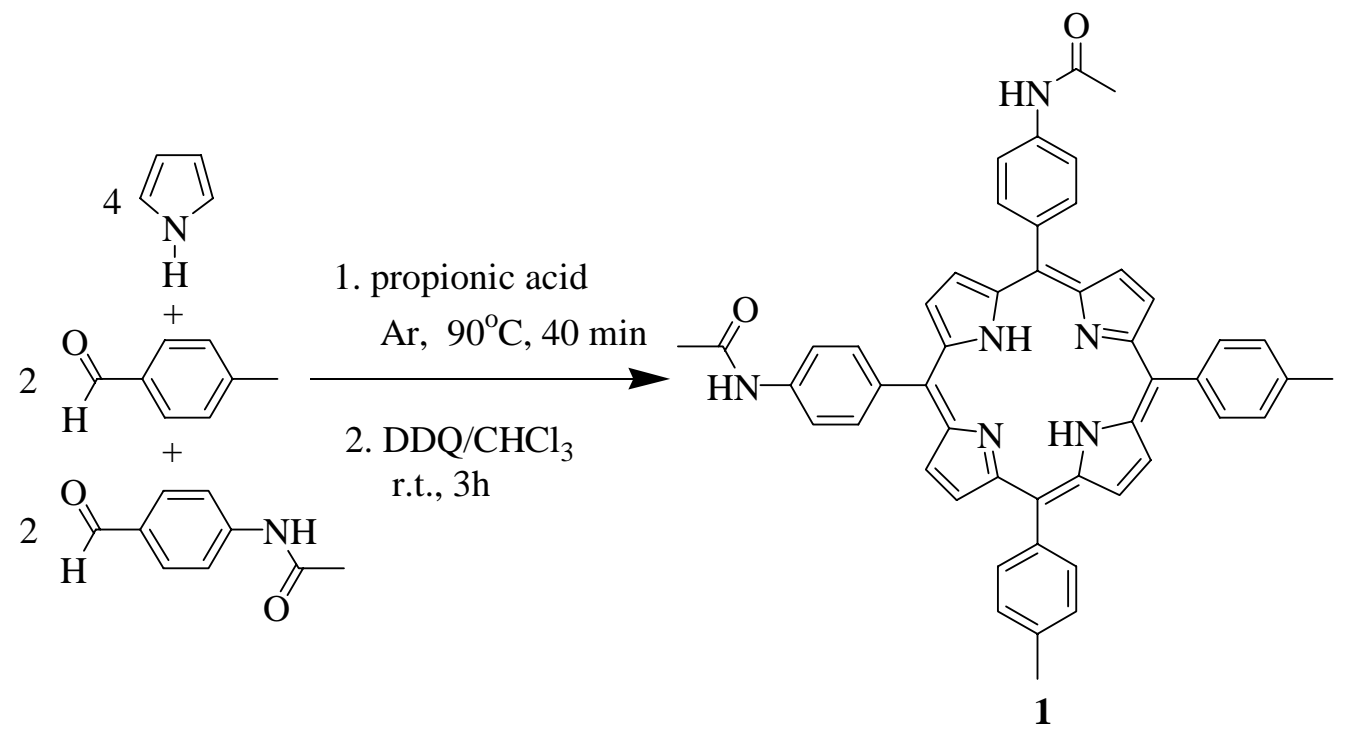

\section{Scheme 1}

To obtain the AABB-porphyrin 1, 4-acetamidobenzaldehyde, 4-methylbenzaldehyde and pyrrole (2:2:4 molar ratio) were heated in propionic acid at $90{ }^{\circ} \mathrm{C}$ for $40 \mathrm{~min}$. The reaction work up difficult because of problems in removing propionic acid and some tar. The mixture was then oxidized with 2,3-dichloro-5,6-dicyano-1,4-benzoquinone (DDQ). The isolation requires a slow and careful chromatographic separation and the yield was very poor (1.4\%). 
5-(4-Trifluoromethylphenyl)-10,15,20-tris(4-acetamidophenyl) porphyrin 2 was synthesized by two different methods. In one case, the $\mathrm{AB}_{3}$-porphyrin 2 was obtained by a condensation of a binary mixture of aldehydes and pyrrole catalyzed by trifluoroacetic acid, TFA, at room temperature (Scheme 2). After treatment with DDQ, the mixture produced porphyrin 2, which was separated by column chromatographic with a yield of $3.6 \%$.

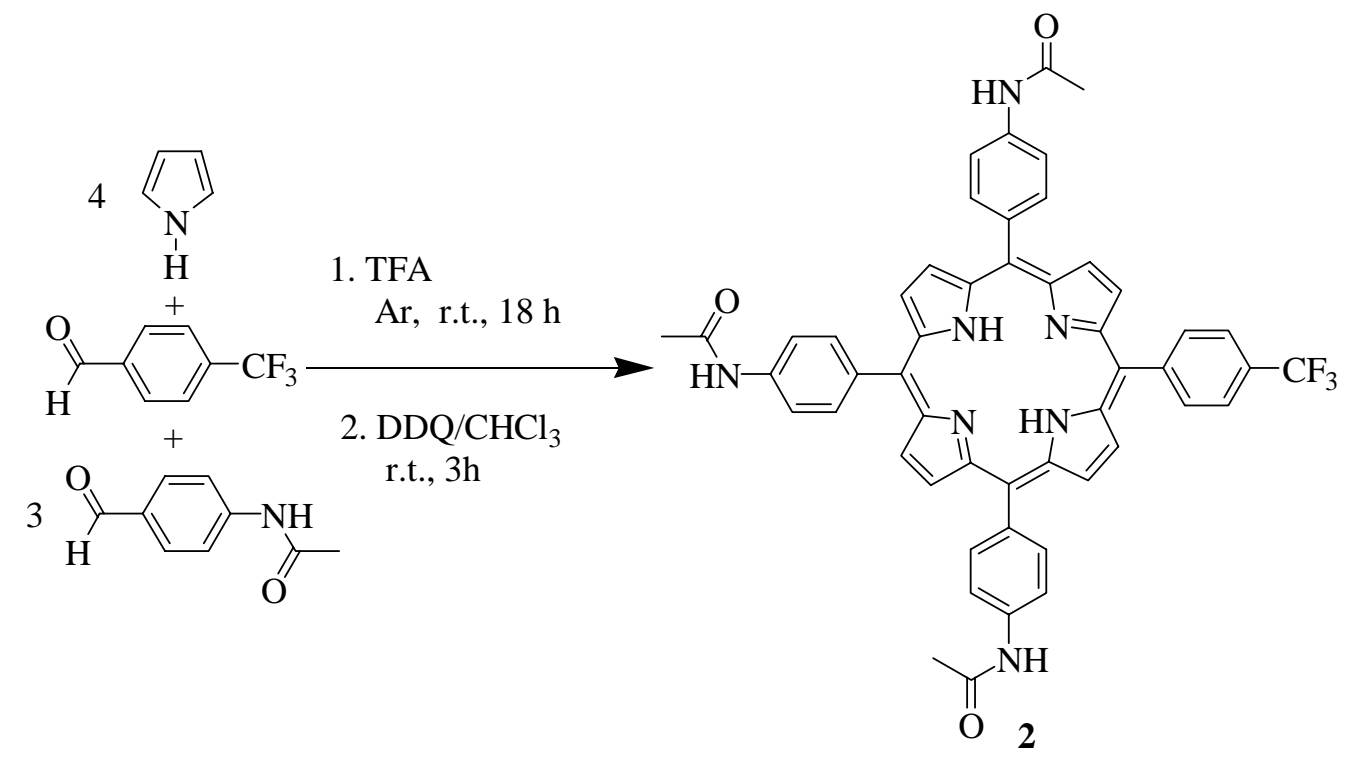

\section{Scheme 2}

The alternative method to synthesize porphyrin 2 involved two steps: 1) formation of meso(4-acetamidophenyl)dipyrromethane 3 (Scheme 3) and 2) condensation of dipyrromethane 3 with the appropriate benzaldehyde mixture (Scheme 4). Thus, dipyrromethane 3 was obtained from the condensation of 4-acetamidobenzaldehyde with a large excess of pyrrole (1:38 aldehyde/pyrrole mol ratio) catalyzed by TFA (Scheme 3). The reaction mixture was stirred for $20 \mathrm{~min}$ at room temperature resulting in the complete disappearance of aldehyde. In these reaction conditions, pyrrole serves as the reactant in excess and as the solvent for the reaction, giving direct formation of dipyrromethane. The brown crude solution was washed with dilute aqueous $\mathrm{NaOH}$. The dipyrromethane 3 was isolated (70 \%) by flash chromatography on silica gel in a mildly basic medium, using ethyl acetate/triethylamine (100:1) as eluent. Under this condition, triethylamine prevents decomposition of the dipyrromethane on silica column, which is slightly acidic. Dipyrromethane 3 is stable in the purified form upon storage at $0^{\circ} \mathrm{C}$ in nitrogen atmosphere and absence of light. Then, dipyrromethane $\mathbf{3}$ was condensed with 4acetamidobenzaldehyde and 4-trifluoromethylbenzaldehyde [2:0.9:1.1 mol ratio, respectively] under catalysis by TFA and at room temperature to form a mixture of porphyrins. The reaction was catalyzed by TFA at room temperature. After oxidation with DDQ, the desired amido porphyrin 2 (15\%) was separated by flash chromatography. 


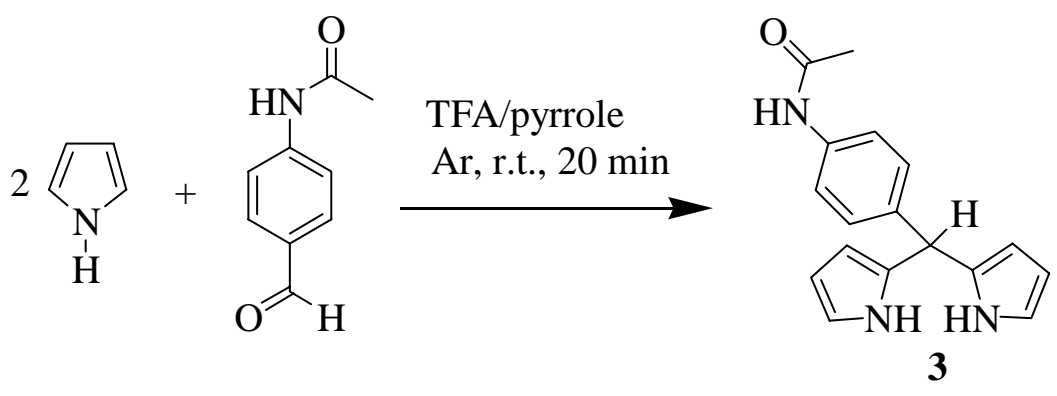

\section{Scheme 3}

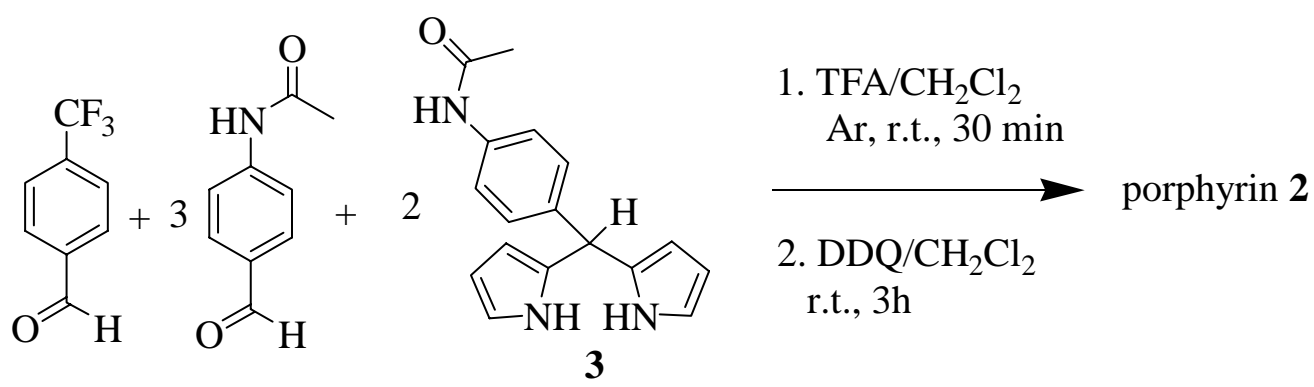

\section{Scheme 4}

Both amido porphyrins, 1 and 2, were hydrolyzed in basic medium to afford the corresponding 5,10-bis(4-aminophenyl)-15,20-bis(4-methylphenyl)porphyrin and 5-(4trifluoromethylphenyl)-10,15,20-tris(4-aminophenyl)porphyrin with $77 \%$ and $74 \%$ yields, respectively (Scheme 5 and 6). Treatment of amino porphyrins with methyl iodide afforded 5,10bis(4-methylphenyl)-15,20-bis(4-trimethylammoniumphenyl)porphyrin iodide 4 (Scheme 5) and 5-(4-trifluorophenyl)-10,15,20-tris(4-trimethylammoniumphenyl)porphyrin iodide 5 (Scheme 6) with $93 \%$ and $95 \%$ yields, respectively.

The treatment of porphyrin 5 with $\mathrm{PdCl}_{2}$ in DMF produces the metallo complex $\mathrm{Pd}(\mathrm{II})$ porphyrin 6 (93\%) (Scheme 6). 


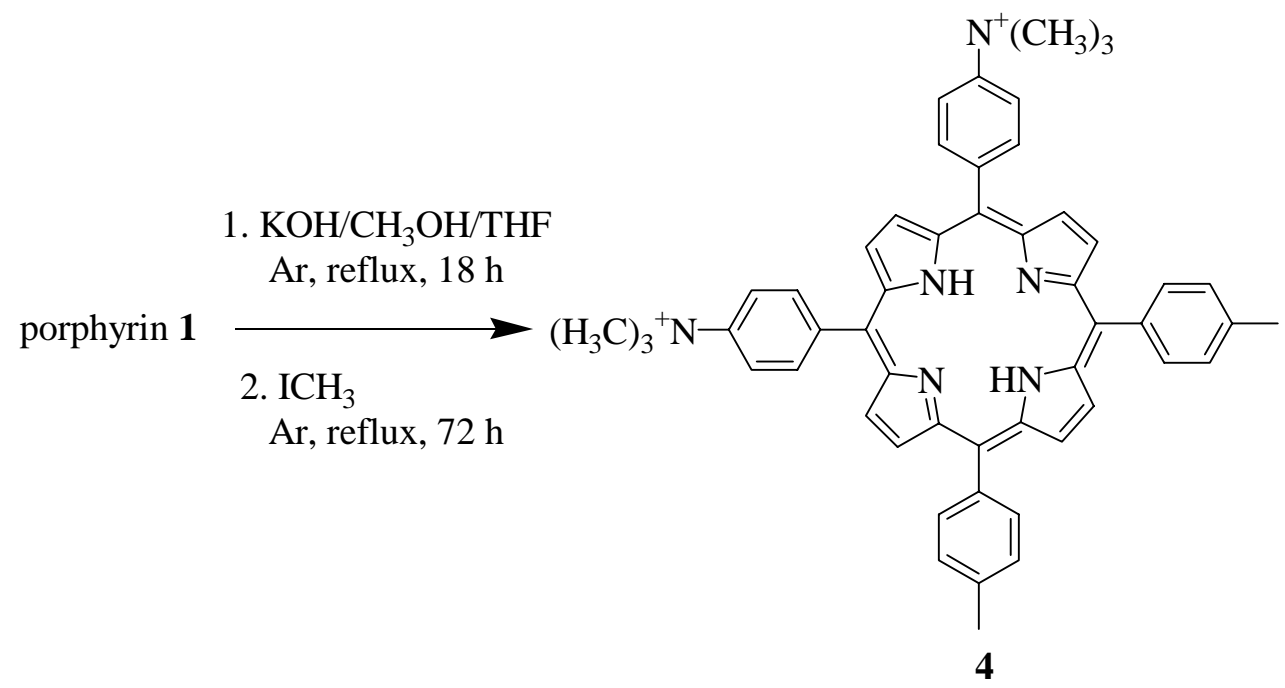

\section{Scheme 5}

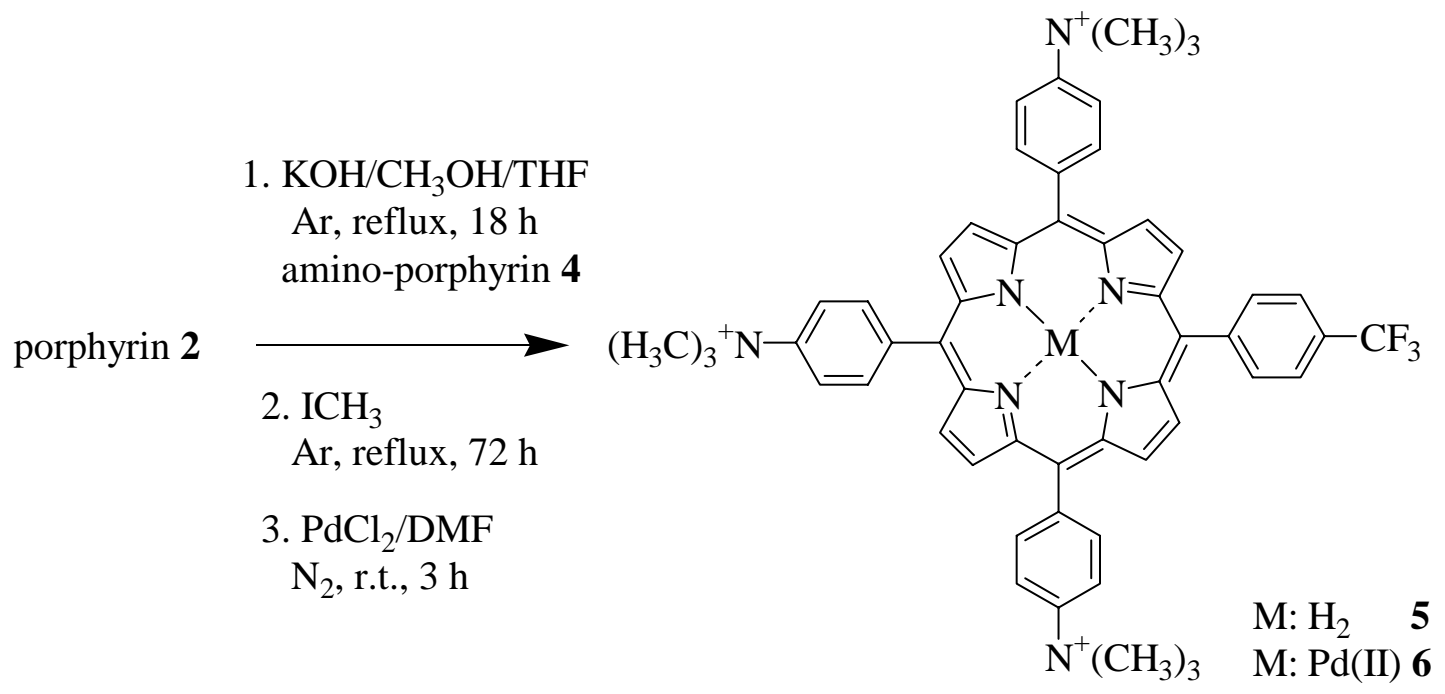

\section{Scheme 6}

\section{Porphyrin properties and spectroscopic studies}

Porphyrin 4 bears two 4-methylphenyl groups and two cationic 4-trimethylammoniumphenyl groups with a AABB-porphyrin symmetry, while porphyrin $\mathbf{5}$ contains one 4trifluoromethylphenyl group and three 4-trimethylammoniumphenyl groups. To evaluate the effect produced by this distribution of different polarity groups upon the intramolecular polarity, the dipole moments of the porphyrins were estimated. The semi-empirical method for molecular modeling (AM1) was used in structure geometry optimization calculations. Values of $39.7 \mathrm{D}$ and 39.9 D were found for $\mathbf{4}$ and 5, respectively. These values are approximately 10 times higher that of the corresponding porphyrin models substituted by amino and methyl groups. As expected, 
the presence of cationic groups in the periphery of porphyrins considerably enhances the dipole moment with respect to the non-charged structure. In particular, for porphyrin 5, a trifluoromethyl group produces an increase from $25.4 \mathrm{D}$ to $39.9 \mathrm{D}$ with respect to a methyl group.

The absorption spectrum of porphyrins 4, 5 and $\mathbf{6}$ in methanol show the typical Soret and Qbands characteristic of free-base porphyrin derivatives and their metal-complex (Figure 1A). ${ }^{37}$ The spectra of porphyrins were also recorded in different solvents. The absorption maxima are summarized in Table 1. The solvatochromic effect on the location of Soret absorption band shows a slight blue shift upon solubilization in methanol.
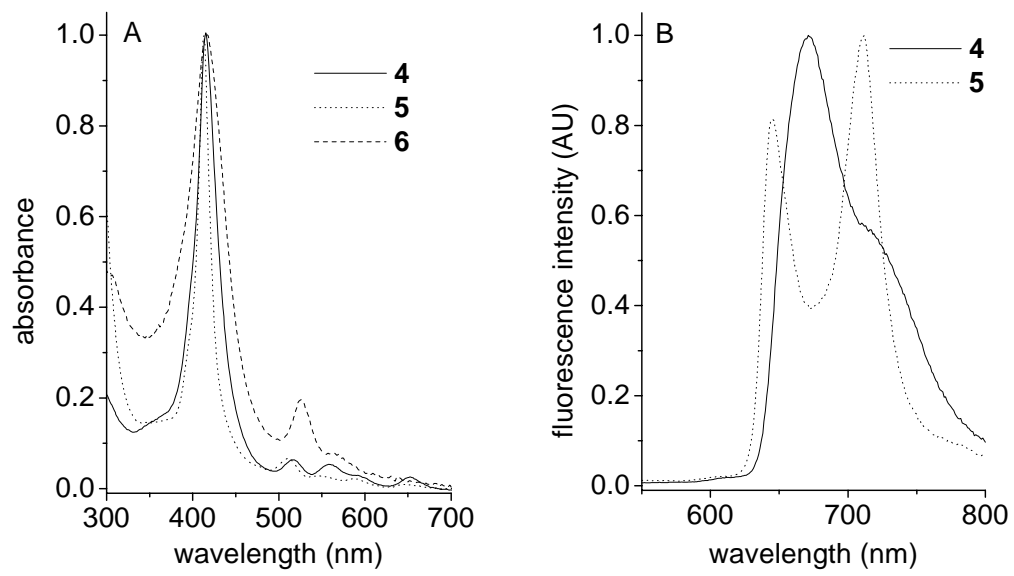

Figure 1. Absorption spectra (A) and fluorescence emission spectra (B) of porphyrin 4 (solid line), 5 (dotted line) and 6 (dashed line) in methanol, $\lambda_{\text {exc }}=515 \mathrm{~nm}$.

Table 1. Absorption and fluorescence emission data for porphyrin 4 in different solvents

\begin{tabular}{lccccccc}
\hline Solvent & \multicolumn{9}{c}{ Absorption $\lambda_{\max }(\mathrm{nm})$} & \multicolumn{1}{c}{ Emission $\lambda_{\max }(\mathrm{nm})$} \\
\hline DCM & 420 & 520 & 563 & 593 & 654 & 670 & 726 \\
DMSO & 419 & 519 & 567 & 591 & 655 & 657 & 715 \\
Methanol & 415 & 516 & 558 & 591 & 652 & 669 & - \\
\hline \multicolumn{7}{c}{ porphyrin 5 } \\
\hline DCM & 418 & 514 & 551 & 588 & 649 & 658 & 712 \\
DMSO & 418 & 513 & 549 & 589 & 647 & 649 & 712 \\
Methanol & 413 & 511 & 547 & 587 & 646 & 647 & 711 \\
\hline \multicolumn{7}{c}{ porphyrin 6 } \\
\hline DCM & 420 & 528 & 568 & - & - \\
DMSO & 418 & 529 & 574 & - & - \\
Methanol & 416 & 526 & \multicolumn{7}{c}{566} & - & - \\
\hline
\end{tabular}


The steady-state fluorescence emission spectra of porphyrins $\mathbf{4}$ and $\mathbf{5}$ in methanol are shown in Figure 1B. No emission from the $\mathrm{Pd}(\mathrm{II})$ porphyrin 6 was detected. Two bands are characteristic for porphyrin derivatives and they have been assigned to $\mathrm{Q}(0-0)$ and $\mathrm{Q}(0-1)$ transitions. Also, a small Stokes shift is expected for tetraphenylporphyrin derivatives indicating that the spectroscopic energy is nearly identical to the relaxed energy of the singlet state. ${ }^{38}$

\section{Conclusions}

Two different approaches were compared in the synthesis of 5-(4-trifluorophenyl)-10,15,20tris(4-acetamidophenyl)porphyrin 2. One involved a condensation of binary mixture of aldehydes and pyrrole and the other a binary mixture of aldehydes and meso-(4acetamidophenyl)dipyrromethane $\mathbf{3}$ catalyzed by acid. The last synthetic pathway was advantageous mainly for a relatively simpler reaction work up and higher yield ( $\sim 4$ times) than the reaction in the presence of pyrrole. However, this approach can not be used to synthesize AABB-porphyrin patterns, such as $\mathbf{1}$. Thus, porphyrin $\mathbf{1}$ was obtained by the first method with a low yield. Both amido porphyrin 1 and $\mathbf{2}$ were hydrolyzed in basic media and treated with methyl iodide to form dicationic $\mathbf{4}$ and tricationic $\mathbf{5}$ porphyrin derivatives, respectively. Porphyrin 5 bears a highly lipophilic trifluoromethyl group, which increases the amphiphilic character of the structure. On the other hand, the photodynamic properties of porphyrin $\mathbf{5}$ were changed by forming metal complex with $\mathrm{Pd}(\mathrm{II})$, porphyrin 6. These amphiphilic cationic porphyrins offer a promising molecular architecture for photosensitizer agents with potential applications in bacteria inactivation by photodynamic treatment. Studies of photosensitization in vitro, using Gram-negative bacteria Escherichia coli, are presently in progress in our laboratory.

\section{Experimental Section}

General Procedures. UV-visible and fluorescence spectra were recorded on a Shimadzu UV2401PC spectrometer and on a Spex FluoroMax fluorometer, respectively. Proton nuclear magnetic resonance $\left({ }^{1} \mathrm{H} \mathrm{NMR}\right)$ spectra were recorded on a Bruker ARX 300 multinuclear spectrometer at $300 \mathrm{MHz}$. Mass Spectra were taken with a Varian Matt 312 operating in EI mode at $70 \mathrm{eV}$. Silica gel (230-400 mesh, Merk) was used for column chromatography. Alumina neutral (150 mesh, Aldrich) was employed. Silica gel thin-layer chromatography (TLC) plates 250 microns from Aldrich (Milwaukee, WI, USA) were used. All the chemicals from Aldrich were used without further purification. Solvents (GR grade) from Merck were distilled. Semiempirical molecular orbital calculations (AM1) were carried out using HyperChem software. 
5,10-bis(4-Acetamidophenyl)-15,20-bis(4-methylphenyl)porphyrin (1). A solution of 4methylbenzaldehyde (3.42 g, $21 \mathrm{mmol}$ ) and 4-acetamidobenzaldehyde (2.52 g, $21 \mathrm{mmol})$ in propionic acid $(150 \mathrm{~mL})$ was stirred at $90{ }^{\circ} \mathrm{C}$ and pyrrole $(3.0 \mathrm{~mL}, 42 \mathrm{mmol})$ was slowly added. The resulting mixture was heated to reflux for $40 \mathrm{~min}$. The mixture was poured into of water $(500 \mathrm{~mL})$, containing of $\mathrm{NaCl}(20 \mathrm{~g})$. The precipitated material was collected by vacuum filtration and dried under vacuum at $100{ }^{\circ} \mathrm{C}$ for 48 hours to remove propionic acid. The resulting material was dissolved in chloroform/methanol (5\%) and filtered through a short column of alumina $(5 \mathrm{~cm})$. This procedure was repeated using silica gel. The solvents were removed under reduced pressure and the residue treated with DDQ (2.27 g, $10 \mathrm{mmol}$ ) in $200 \mathrm{~mL}$ of chloroform for 3 hours. The solvent was evaporated and the residue was pulverized to a fine powder. Slow chromatographic column (silica gel, chloroform/methanol gradient) afforded porphyrin $\mathbf{1}$ (purple solid, $111 \mathrm{mg}, 1.4 \%$ ) as second moving band. TLC analysis (dichloromethane/methanol 5\%) $\mathrm{R}_{\mathrm{f}}$ 0.35. ${ }^{1} \mathrm{HNMR}\left(\mathrm{CDCl}_{3}\right.$, TMS) $\delta$ [ppm] -2.78 (brs, 2H, pyrrole $\left.\mathrm{N}-\mathrm{H}\right), 2.34$ (s, 6H, $\left.\mathrm{COCH}_{3}\right), 2.70$ (s, 6H, Ar- $\mathrm{CH}_{3}$ ), 7.56 (d, 4H, J=7.9Hz, 5,10-Ar 3,5-H), 7.46 (brs, 2H, NHCO), 7.87 (d, 4H, $\mathrm{J}=8.0 \mathrm{~Hz}, 15,20-\mathrm{Ar} 3,5-\mathrm{H}), 8.10$ (d, 4H, J=7.9Hz, 5,10-Ar 2,6-H), 8.17 (d, 4H, J=8.0 Hz, 15,20Ar 2,6-H), 8.75 (s, 2H, $\beta$-pyrrole), 8.80 (d, 2H, J= 4.9 Hz, $\beta$-pyrrole), 8.86 (d, 2H, J= 4.9 Hz, $\beta$ pyrrole), 8.90 (s, $2 \mathrm{H}, \beta$-pyrrole). MS m/z $756\left(\mathrm{M}^{+}\right)$(756.3213 calculated for $\left.\mathrm{C}_{50} \mathrm{H}_{40} \mathrm{~N}_{6} \mathrm{O}_{2}\right)$. Anal. calcd. C 79.34, H 5.33, N 11.10; found C 79.27, H 5.38, N 11.06.

meso-(4-Acetamidophenyl)dipyrromethane (3). A solution of 4-acetamicobenzaldehyde (2.45 g, $15 \mathrm{mmol})$ and pyrrole $(40.0 \mathrm{~mL}, 576 \mathrm{mmol})$ was degassed by bubbling with argon for 15 min. Then trifluoroacetic acid $(210 \mu \mathrm{L}, 2.7 \mathrm{mmol})$ was added. The solution was stirred for 20 min at room temperature, at which point no starting aldehyde was shown by TLC analysis (ethyl acetate/triethylamine 100:1). The mixture was treated with aqueous $\mathrm{NaOH}(0.1 \mathrm{M}, 50 \mathrm{~mL})$ and extracted with dichloromethane $(2 \times 50 \mathrm{~mL})$. The solvent was removed under reduced pressure. The unreacted pyrrole was removed by vacuum distillation at room temperature. The product was purified by flash chromatography (silica gel, cyclohexane/ethyl acetate/triethylamine, 60:40:1 and then ethyl acetate/triethylamine 100:1) to give dipyrromethane 3 (2.92 g $70 \%)$ TLC (silica gel) Rf (ethyl acetate/triethylamine 100:1) $=0.17 .{ }^{1} \mathrm{HNMR}$ (DMSO-d 6 , TMS) $\delta$ [ppm] 2.20 (s, 3H, $\mathrm{COCH}_{3}$ ), 5.47 (s, 1H, meso-H), 5.83 (m, 2H, pyrrole-H), 6.08 (q, 2H, pyrrole-H), 6.78 (d, 2H, pyrrole-H), 7.26 (d, 2H, J = 8.6 Hz, Ar 2,6-H), 7.64 (d, 2H, J = 8.6 Hz, Ar 3,4-H), 10.05 (s, brs, 1H, HNCO), 10.69 (s, brs, 2H, pyrrole NH). MS [m/z] $279\left(\mathrm{M}^{+}\right)(279.1372$ calculated for $\mathrm{C}_{17} \mathrm{H}_{17} \mathrm{~N}_{3} \mathrm{O}$ ). Anal. calcd. C 73.10, H 6.13, N 15.04; found C 73.23, H 6.20, N 15.01 .

5-(4-Trifluoromethylphenyl)-10,15,20-tris(4-acetamidophenyl)porphyrin (2). A solution of 4-acetamidobenzaldehyde (757 mg, $4.64 \mathrm{mmol}$ ), 4-trifluorobenzaldehyde (985 mg, $5.66 \mathrm{mmol}$ ) and meso-(4-acetamidophenyl)dipyrrometane 3 (2.87 g, $10.27 \mathrm{mmol})$ in dichloromethane (1 L) was purged with argon for $15 \mathrm{~min}$. Then TFA (1.40 mL, $3.5 \mathrm{mmol})$ was slowly added. The solution was stirred for $30 \mathrm{~min}$ at room temperature. Then, DDQ (6.80 g, $30.0 \mathrm{mmol})$ was added and the mixture was stirred for an additional $1.5 \mathrm{~h}$ at reflux. The solvent was removed under reduced pressure and flash column chromatography (silica gel, dichloromethane/methanol 8\% 
gradient to $12 \%$ ) yielded the pure selected porphyrin 2 (purple solid, $610 \mathrm{mg}, 15 \%$ ) as the second porphyrin band. TLC analysis (dichloromethane/methanol $7 \%) \mathrm{R}_{\mathrm{f}} 0.37 .{ }^{1} \mathrm{HNMR}\left(\mathrm{CDCl}_{3}\right.$, TMS) $\delta$ [ppm] -2.88 (brs, 2H, pyrrole N-H), 2.30 (s, 9H, $\mathrm{COCH}_{3}$ ), 7.45 (brs, 3H, NHCO), 7.84 (d, 6H, J=8.1 Hz, 10,15,20-Ar 3,5-H), 7.93-7.98 (m, 4H, 5-Ar), 8.09 (d, 6H, J=8.1 Hz, 10,15,20Ar 2,6-H); 8.69 (d, 2H, J=4.8 Hz, $\beta$-pyrrole), 8.79-8.83 (m, 6H, $\beta$-pyrrole). MS m/z $853\left(\mathrm{M}^{+}\right.$) (853.2988 calculated for $\mathrm{C}_{51} \mathrm{H}_{38} \mathrm{~F}_{3} \mathrm{~N}_{7} \mathrm{O}_{3}$ ). Anal. calcd. C 71.74, $\mathrm{H}$ 4.49, $\mathrm{N}$ 11.48; found $\mathrm{C} 71.66$, H 4.55, N 11.39.

Also, porphyrin 2 was synthesized from a mixture of 4-acetamidobenzaldehyde (130.5 mg, $0.80 \mathrm{mmol}$ ), 4-trifluorobenzaldehyde (46.4 $\mathrm{mg}, 0.27 \mathrm{mmol}$ ) and pyrrol (74 $\mu \mathrm{L}, 1.07 \mathrm{mmol})$ in $50 \mathrm{~mL}$ of dichloromethane. After purging the solution with argon for $15 \mathrm{~min}$, TFA (950 $\mu \mathrm{L}$, $12.33 \mathrm{mmol}$ ) was slowly added to the mixture that was magnetically stirred over night at room temperature. Then the mixture was treated with DDQ (100mg, $0.44 \mathrm{mmol})$ for $3 \mathrm{~h}$. The solvent was removed and porphyrin 2 (8 mg, $3.5 \%$ ) was isolated by column chromatography (silica gel, dichloromethane/methanol $8 \%$ gradient to $12 \%)$.

5,10-Bis(4-methylphenyl)-15,20-bis(4-trimethylammoniumphenyl)porphyrin iodide (4). Amido porphyrin 1 (60 mg, $0.079 \mathrm{mmol}$ ) was dissolved in $30 \mathrm{~mL}$ of THF/methanol (1:1, $30 \mathrm{~mL}$ ) and aqueous $\mathrm{KOH}(50 \% \mathrm{w} / \mathrm{v}, 30 \mathrm{~mL}$ ) was added. The reaction mixture was stirred under a nitrogen atmosphere for $18 \mathrm{~h}$ at reflux. Then, the mixture was diluted with dichloromethane $(100 \mathrm{~mL})$ and washed with aqueous sodium carbonate $(0.1 \mathrm{M}, 50 \mathrm{~mL})$. The organic solvent was evaporated under reduced pressure. Flash column chromatography (silica gel, dichloromethane/methanol $3 \%$ afforded 5,10-bis(4-aminophenyl)-15,20-bis(4trifluoromethylphenyl)porphyrin (purple solid, $41 \mathrm{mg}, 77 \%$ ). TLC analysis (dichloromethane/methanol 5\%) $\mathrm{R}_{\mathrm{f}}$ 0.66. MS m/z $672\left(\mathrm{M}^{+}\right)\left(672.3001\right.$ calculated for $\left.\mathrm{C}_{46} \mathrm{H}_{36} \mathrm{~N}_{6}\right)$. The crude amino-porphyrin (30 mg, $0.045 \mathrm{mmol}$ ) was refluxed in $4 \mathrm{~mL}$ of methyl iodide under argon atmosphere for $72 \mathrm{~h}$. The solvent was removed under reduced pressure and the solid, after washing with diethyl ether, yielded porphyrin 4 (42 mg, $93 \%$ ). ${ }^{1} \mathrm{HNMR}$ (DMSO- $\mathrm{d}_{6}$, TMS) $\delta$ [ppm] -2.92 (brs, 2H, pyrrole $\mathrm{N}-\mathrm{H}$ ), 2.71 (s, 9H, $-\mathrm{CH}_{3}$ ), 3.90 (s, 18H, N-CH $), 7.14$ (d, 4H, $\mathrm{J}=8.4 \mathrm{~Hz}, 15,20-\mathrm{Ar}$ 3,5-H), 7.62 (d, 4H, J=8.0 Hz, 5,10-Ar 3,5-H), 8.00 (d, 4H, J=8.4 Hz, 15,20Ar 2,6-H), 8.07 (d, 4H, J=8.0 Hz, 5,10-Ar 2,6-H), 8.74 (s, 2H, $\beta$-pyrrole), 8.82 (d, 2H, J= 4.9 Hz, $\beta$-pyrrole), 8.87 (d, 2H, J= $4.9 \mathrm{~Hz}, \beta$-pyrrole), 8.92 (s, 2H, $\beta$-pyrrole). MS m/z 758 (M $\left.{ }^{+}-2 \mathrm{I}\right)$ (758.4097 calculated for $\mathrm{C}_{52} \mathrm{H}_{50} \mathrm{~N}_{6}$ ). Anal. calc. C 61.67, H 4.98, N 8.30; found C 61.58, H 4.90, N 8.38. Absorption spectrum $\lambda_{\max }$ (methanol) [nm] ( $\left.\varepsilon, \mathrm{dm} 3 \mathrm{~mol}-1 \mathrm{~cm}-1\right) 415$ (164 000), 516 (8 900), 558 (4 700) 652 (4 200).

5-(4-Trifluoromethylphenyl)-10,15,20-tris(4-trimethylammoniumphenyl)porphyrin iodide (5). To a solution of amido-porphyrin 2 (100 mg, $0.117 \mathrm{mmol})$ in THF/methanol (1:1, $40 \mathrm{~mL})$ was added aqueous $\mathrm{KOH}(50 \% \mathrm{w} / \mathrm{v}, 40 \mathrm{~mL})$. The reaction mixture was stirred under an argon atmosphere for $18 \mathrm{~h}$ at reflux. Then, the mixture was diluted with dichloromethane $(100 \mathrm{~mL})$ and washed with aqueous sodium carbonate $(0.1 \mathrm{M}, 50 \mathrm{~mL})$. The organic solvent was evaporated under reduced pressure. Flash chromatography column (silica gel, dichloromethane/methanol/triethylamine 98.5:1.5:1) afforded 5-(4-trifluoromethylphenyl)- 
10,15,20-tris(4-aminophenyl)porphyrin (purple solid, $63 \mathrm{mg}, 74 \%$ ). TLC analysis (dichloromethane/methanol/triethylamine 98.5:1.5:1) $\mathrm{R}_{\mathrm{f}}$ 0.63. $\mathrm{MS}$ m/z $727\left(\mathrm{M}^{+}\right)(727.2671$ calculated for $\mathrm{C}_{45} \mathrm{H}_{32} \mathrm{~F}_{3} \mathrm{~N}_{7}$ ). The crude amino-porphyrin (50 mg, $0.069 \mathrm{mmol}$ ) was refluxed in methyl iodide $(4 \mathrm{~mL})$ under argon atmosphere for $72 \mathrm{~h}$. The solvent was removed under reduced pressure and the solid washed with $n$-heptane to yield porphyrin 5 (81 mg, $95 \%$ ). ${ }^{1} \mathrm{HNMR}$ (DMSO-d $\left.\mathrm{D}_{6}, \mathrm{TMS}\right) \delta$ [ppm] -2.93 (brs, 2H, pyrrole N-H), 3.94 (s, 27H, N-CH $), 7.17$ (d, 6H, $\mathrm{J}=8.1 \mathrm{~Hz}, 10,15,20-\mathrm{Ar}$ 3,5-H), 7.92-7.98 (m, 4H, 5-Ar), 8.03 (d, 6H, J=8.1 Hz, 10,15,20-Ar 2,6H), 8,83 (d, 2H, J=4.8 Hz, $\beta$-pyrrole), 8.70-8.98 (m, 6H, $\beta$-pyrrole). MS m/z $856\left(\mathrm{M}^{+}-3 \mathrm{I}\right)$ (856.4315 calculated for $\mathrm{C}_{54} \mathrm{H}_{53} \mathrm{~F}_{3} \mathrm{~N}_{7}$ ). Anal. calc. C 52.40, $\mathrm{H}$ 4.32, $\mathrm{N}$ 7.92; found $\mathrm{C} \mathrm{52.48,} \mathrm{H}$ 4.27, N 7.96. Absorption spectrum $\lambda_{\max }$ (methanol) $[\mathrm{nm}]\left(\varepsilon, \mathrm{dm}^{3} \mathrm{~mol}^{-1} \mathrm{~cm}^{-1}\right) 413$ (170 000), 511 (11 100), 547 (4 700) 587 (3 700) 646 (3 000)

Palladium 5-(4-trifluoromethylphenyl)-10,15,20-tris(4-trimethylammoniumphenyl) porphyrin iodide (6). To a solution of porphyrin 5 (10 mg, $0.008 \mathrm{mmol})$ in DMF (5 mL) was added palladium(II) chloride (10 mg, $0.056 \mathrm{mmol}$ ). The mixture was stirred for $5 \mathrm{~h}$ at reflux in atmosphere of argon. The solvent was removed under vacuum, the solid was redissolved in dichloromethane, filtered and dried to yield porphyrin 6 (dark purple solid, $10 \mathrm{mg}, 93$ \%). MS m/z 960 ( $\mathrm{M}^{+}$-3I) (960.3193 calculated for $\left.\mathrm{C}_{54} \mathrm{H}_{51} \mathrm{~F}_{3} \mathrm{~N}_{7} \mathrm{Pd}\right)$. Anal. calc. C 48.32, H 3.83, N 7.31; found C 48.23, H 3.91, N 7.25. Absorption spectrum $\lambda_{\max }$ (methanol) $[\mathrm{nm}]\left(\varepsilon, \mathrm{dm}^{3} \mathrm{~mol}^{-1} \mathrm{~cm}^{-1}\right) 416$ (168 000), 526 (19 000), 566 (3 800).

\section{Acknowledgments}

Authors are grateful to Consejo Nacional de Investigaciones Científicas y Técnicas (CONICET) of Argentina, Agencia Nacional de Promoción Científica y Tecnológica, Third World Academy of Sciences (TWAS) and Fundación Antorchas for financial support. Thank to Dra. S. D. Mandolesi for NMR experiments. E.N.D. is Scientific Members of CONICET. D.L. thank Fundación Antorchas for a research fellowship.

\section{References}

1. Milgrom L. R.; O’Neill, F. “Porphyrins”, Ch. 8. In The Chemistry of Natural Products, R. H. Thomson, Ed.; Blackie Academic \& Professional: London, 1993, pp 329-376.

2. Grosseweiner, L. I. "Photodynamic therapy”, Ch. 8, In The Science of Phototherapy, CRC Press: London, 1994, pp 139-155.

3. McCaughan Jr, J. S. Drugs \& Aging 1999, 15, 49.

4. Henderson, B. W.; Dougherty, T. J. Photochem. Photobiol. 1992, 55, 145.

5. Penning, L. C.; Dubbelman, T. M. Anti-Cancer Drugs 1994, 5, 139. 
6. Bonnett, R. Chemical Aspects of Photodynamic Therapy, Advanced Chemistry Texts; Gordon and Breach Science Publishers: Amsterdam, 2000.

7. Villanueva, A. J. Photochem. Phorobiol. B: Biol. 1993, 18, 295.

8. Ali, H.; van Lier, J. E. Chem. Rev. 1999, 99, 2379.

9. Haylett, A. K.; McNair, F. I.; McGarvey, D.; Dodd, N. J. F.; Forbes, E.; Truscott T. G.; Moore, J. V. Cancer Lett. 1997, 112, 233.

10. Ravanat, J-L.; Cadet, J.; Araki, K.; Toma, H. E.; Medeiros M. H. G.; Di Mascio, P. Photochem. Photobiol. 1998, 68, 698.

11. Garbo, G. M.; Fingar, V. H.; Wieman, T. J.; Noakes III, E. B.; Haydon, P. S.; Cerrito, P. B.; Kessel D. H.; Morgan, A. R. Photochem. Photobiol. 1998, 68, 561.

12. Kubát, P.; Lang, K.; Anzenbacher Jr., P.; Jursíková, K.; Král V.; Ehrenberg, B. J. Chem. Soc., Perkin Trans. 1 2000, 933.

13. Mettath, S.; Munson B. R.; Pandey, R. K. Bioconjugate Chem. 1999, 10, 94.

14. Taylor, P. W.; Stapleton, P. D.; Luzio J. P. Drug Discovery Today 2002, 7, 1086.

15. Nitzan Y.; Asquenazí, H. Current Microbiol. 2001, 42, 408.

16. Merchat, M.; Spikes, J. D.; Bertoloni, G.; Jori, G. J. Photochem. Photobiol. B: Biol. 1996, 35, 149.

17. Merchat, M.; Bertoloni, G.; Giacomini, P.; Villanueva, A.; Jori, G. J. Photochem. Photobiol. B: Biol. 1996, 32,153.

18. Li, H.; Fedorova, O. S.; Grachev, A. N.; Trumble, W. R.; Bohach, G. A.; Czuchajowski, L. Biochim. Biophys. Acta 1997, 1354, 252.

19. Weitemeyer, A.; Kliesch, H.; Michelsen, U.; Hirth A.; Wöhrle, D. "Unsymmetrically substituted porphyrazines", In Photodynamic tumor therapy, 2nd and 3rd genaration photosensitizers, Ed. Moser, J. G. Harwood Academic Publishers: Amsterdam; 1998, Ch. 2.6, pp 87-99.

20. Milanesio, M. E.; Alvarez, M. G.; Silber, J. J.; Rivarola, V.; Durantini, E. N. Photochem. Photobiol. Sci. 2003, 9, 926.

21. Gust, D.; Moore, T. A.; Moore, A. L.; Leggett, L.; Lin, S.; DeGraziano, J. M.; Hermant, R. M.; Nicodem, D.; Craig, P.; Seely, G. R.; Nieman, R. A. J. Phys. Chem. 1993, 97, 7926.

22. Gust, D.; Moore, T. A.; Moore, A. L.; Gao, F.; Luttrull, D.; DeGraziano, J. M.; Ma, X. C.; Makings, L. R.; Lee, S-J.; Trier, T. T.; Bittersmann, E.; Seely, G. R.; Woodward, S.; Bensasson, R. V.; Rougée, M.; De Schryver, F. C.; Van der Auweraer, M. J. Am. Chem. Soc. 1991, 113, 3638.

23. Lindsey, S. J.; Schreiman, Y. C.; Hsu, H. C.; Kearney, P. C.; Marguerettaz, A. M. J. Org. Chem. 1987, 52, 827.

24. Lee, C-H.; Lindsey, J. S. Tetrahedron 1994, 50, 11427.

25. Littler, B.J.; Ciringh, Y.; Lindsey, J. S. J. Org. Chem. 1999, 64, 2864.

26. Durantini, E. N.; Silber J. J. Synth. Commun. 1999, 29, 3353. 
27. Durantini E. N. J. Porphyrins Phthalocyanines 2000, 4, 233.

28. McClinton, M. A.; McClinton, D. A. Tetrahedron 1992, 48, 6555.

29. Milanesio, M. E.; Moran, M. S.; Yslas, E. I.; Alvarez, M. G.; Rivarola V.; Durantini E. N. Bioorg. Medicinal Chem. 2001, 9, 1943

30. Villanueva, A.; Durantini, E. N.; Stockert, J. C.; Rello, S.; Vidania, R.; Cañete, M.; Juarranz, A.; Arranz R.; Rivarola V. Anti-Cancer Drug Design 2001, 16, 279.

31. Ando, A.; Kumadaki, I. J. Fluor. Chem. 1999, 100, 135.

32. Grancho, J. C. P.; Pereira, M. M.; Miguel, M. da G.; Rocha Gosnsalves, A. M.; Burrows H. D. Photochem. Photobiol. 2002, 75, 249.

33. Kim, K.; Fancy, D. A.; Carney; D. Kodadek, T. J. Am. Chem. Soc. 1999, 121, 11896.

34. Cañete, M.; Ortiz, A.; Juarraz, A.; Villanueva, A.; Nonell, S.; Borrell, S.; Teixidó, J.; Stockert, J. C. Anti-Cancer Drug Design 2000, 15, 143.

35. Scalise, I.; Durantini, E. N. J. Photochem. Photobiol. A: Chem. 2003, in press JPC 6405.

36. Adler, A. D.; Longo, F. R.; Finarelli, F. C.; Assour, J.; Korsakoff, L. J. Org. Chem. 1967, 32, 476.

37. K. M. Smith, “General features of the structure and chemistry of porphyrin compounds”, In Porphyrins and Metalloporphyrins, Elsevier: Amsterdam, 1975, Ch. 1, pp 20-27.

38. Pineiro, M.; Carvalho, A. L.; Pereira, M. M.; Rocha Gonsalves, A. M. d’A.; Arnaut L. G.; Formosinho, S. J. Chem. Eur. J. 1998, 4, 2299. 